\section{Romarias Quaresmais na Ilha de São Miguel- -Açores: Contributos para o Estudo das Peregrinações Açorianas}

\section{Resumo}

A forte ligação espiritual com o catolicismo, trazido quando do povoamento pelos portugueses e o temor da natureza vulcânica das ilhas Açorianas, traduziu-se no século XVI em uma peregrinação ao redor da ilha durante uma semana. Apelando à benevolência da Virgem através da penitência e oração, ocorre a caminhada onde se realizam paradas quando se deparam com templos católicos no período da Quaresma.

Palavras-chave: Religião. Cristianismo. Romeiros. Quaresma. Açores.

\section{Abstract}

The strong spiritual connection with Catholicism, brought in by the settlement by the Portuguese and the fear of the volcanic nature of the Atlantic islands, was translated in the XVI century in a pilgrimage around the island during a week. Appealing to the Virgin's benevolence through penance and prayer, there is the walk where they make stops when they encounter Catholic temples in the Lenten period.

Keywords: Religion. Christianity. Romeiros. Lent. Azores.

\section{Introdução}

O presente ensaio tem como principal objeto de estudo o fenômeno da religiosidade na ilha de São Miguel, localizada no arquipélago dos Açores, em Portugal, através das romarias quaresmais que ocorrem anualmente.
Prof. ${ }^{a}$ Me. Creusa

Maria Silva Raposo

Doutoranda em Estudos do

Património da Universidade

Católica Portuguesa

Mestre em Patrimônio,

Museologia e Desenvolvimento.

Sociedade Ibero-Americana

de Antropologia Aplicada.

E-mail: creusamsr@gmail.com 


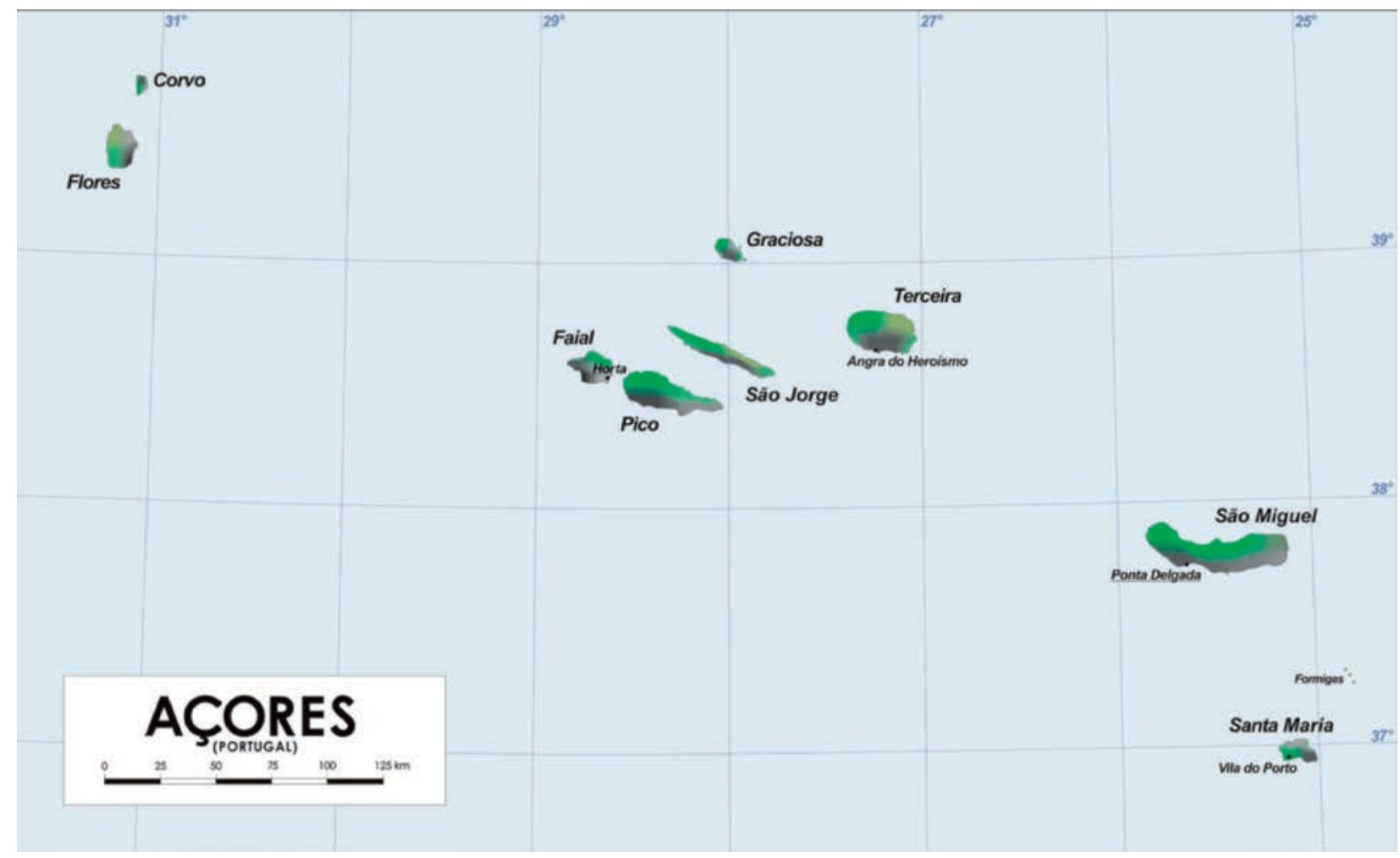

Figura 1 - Arquipélago dos Açores no Oceano Atlântico

Fonte: Wikipedia.org

A ilha de São Miguel Arcanjo, como também é conhecida, quando da sua descoberta em 1432 pelo navegador Gonçalo Velho Cabral, encontrava-se revestida por uma cobertura de árvores altas e arbustos, assim como por um intenso matagal (ALMEIDA, 2012). Deparados com um cenário de natureza indomada, os povoadores portugueses dos anos de quatrocentos e de quinhentos, tiveram de transformá-la e preparar o seu novo habitat (ALMEIDA, 2012).

Esta ilha de São Miguel em que, Senhora, estamos é montuosa e regada de ribeiras, e era logo, quando se achou, coberta de arvoredo, graciosa em sua situação e, por ser húmida com as águas das chuvas e ribeiras e quente do sol, criou tantos e tão espessos arvoredos que com sua sombra conservavam nela esta humidade sempre fresca e durável, com que ela ficou e estava no princípio tão fumosa de tão grossos vapores, sem ter o sol força para os gastar nem penetrar com seus raios, nem os ventos livre entrada para os lançar daqueles lugares sombrios da espessura do arvoredo [...] Mas, o que em longíssimos e antiquíssimos anos foi criado, em tão poucos se queimou, roçou e consumiu quase tudo depois de achada [...]. (FRUTUOSO, 2005)

O sistema administrativo de divisão e posse da terra, baseou-se nas chamadas "dadas" ou "sesmarias", onde o dono da terra tinha a obrigação de construir uma "cafua" e um "curral", roçar o terreno, efetuar benfeitorias e estabelecer acessos para uso comum, atribuídas pelo Capitão do Donatário, a fim de promover a fixação de núcleos familiares (RAPOSO, 2016).

Apesar deste povoamento ter tido maior significado apenas a partir de 1444, a estrutura fundiária se cristalizou muito cedo, em grande parte devido à vinculação dos bens ainda na primeira metade do século $X V I$, restringindo o homem comum ao contrato de locação das terras ou ao trabalho a soldo do proprietário (ALMEIDA, 2012). 
A primeira economia das ilhas tinha como protagonista a produção de trigo, cedro do mato, pastel e urzela (RAPOSO, 2016).

\begin{abstract}
Alguns anos depois do descobrimento e povoação desta ilha, era vila somente Vila Franca do Campo e a cabeça de toda ela, sem haver outra, senão alguns lugares, como suas aldeias, em que havia juízes pedâneos e alcaides, e seus moradores eram obrigados a ir a ela todos os dias de festa principais, em que havia procissões solenes. (FRUTUOSO, 2005)
\end{abstract}

A primeira capital da ilha de São Miguel, Vila Franca do Campo, encontrava-se quase rés-vês com o mar. Alinhada entre a orla da costa rasa e os montes que a circundam ao norte, toda vestida de branco, entre a verdura dos prados e as quintas afamadas com suas igrejas, parece, ainda hoje, acenar aos navios, que cruzaram estas águas atlânticas.

Vila Franca do Campo foi fundada em 1444 por povoadores fixados inicialmente na Povoação Velha e que se deslocaram para sudeste (SANTOS, 1989). No século XVI, devido ao aumento significativo da população, os mesmos solicitaram a el-Rei o estatuto de vila. Desta forma, criou-se a primeira capital da ilha, quando lhes foram entregues as funções políticas e administrativas de natureza civil e religiosa. Segundo Gaspar Frutuoso era a vila mais populosa dos Açores, onde residiam os Ministros da Justiça Eclesiástica e Secular, nobres e fidalgos.

As ilhas foram vitimadas frequentemente por sismos e erupções vulcânicas, das quais a de 1522 foi determinante para o surgimento das romarias quaresmais. Meses antes "do dia do tremor, dia do mistério, o dia do dilúvio", mais concretamente, em 22 de outubro de 1522, chegou à ilha de São Miguel, o Frei Afonso de Toledo. Este, considerou a ilha um paraíso e julgou que os seus habitantes tinham perdido o temor a Deus.

Assim, nas suas pregações e sermões, apelou à penitência e oração para que não houvesse castigos divinos (FRUTUOSO, 2005). Porém, na madrugada do mesmo dia, uma quarta-feira, por voltas das 2 horas, o céu estava estrelado, com ausência de vento e de nuvens, e com tempo sereno, quando

\begin{abstract}
[...] começou a tremer a terra mais que outras vezes tremia, e a dar fortes balanços, parecendo maresia [...] exaltações senão de minerais de salitre e enxofre, que cresciam muito debaixo da terra [...] se sentiu em toda a ilha um grandíssimo e espantoso tremor de terra, que durou o espaco de um Credo, em que parecia que os elementos, fogo, ar e água, pelejavam no centro dela, fazendo-a dar grandes abalos, com roncos e movimentos horrendos, como ondas de mar furioso, parecendo a todos os moradores da ilha, que virava o centro dela para cima e que o céu caía. (FRUTUOSO, 2005)
\end{abstract}

O terremoto apanhou as pessoas desprevenidas e vitimou grande parte da população e fez ruir as habitações e edificações nobres da vila, provocando o seu desabamento. As grotas encheram-se de lodo e lama arrastando consigo árvores, pedregulhos, animais e até mesmo pessoas, provocando um enorme aluimento de terras que soterrou a primeira capital de São Miguel, provocando a morte da esmagadora maioria dos seus habitantes.

Teve epicentro nas proximidades de Vila Franca do Campo, que foi subvertida por uma montanha que se despenhou atingindo $10 \mathrm{na}$ escala de Mercalli e sentido em toda a ilha, mas com intensidade significativa em Ponta Garça, Água do Pau, Furnas, Fenais da Ajuda e Maia. Para além disso o enorme escoamento de terra ao entrar no mar e ao dissipar-se formou uma forte ondulação, que afectou algumas embarcações ancoradas perto do Ilhéu de Vila Franca do Campo, devido ao impacto e volume de água deslocada. Sucederam ao sismo três grandes réplicas, mas de menor duração atingindo 8 na referida escala (SANTOS, 1989).

A tragédia que arrasou a vila provocou temor ao ponto de alguns habitantes partirem para o reino e se estabelecerem em outras localidades 
da ilha, nomeadamente na vila de Ponta Delgada. Os que permaneceram, temerosos que os seus dias estivessem próximos do fim, realizaram procissões, eucaristias, penitências e esmolas, iniciando uma romaria ao redor da ilha e invocando a proteção da Virgem Maria (FRUTUOSO, 2005).

\section{As romarias quaresmais}

As origens das romarias quaresmais são frequentemente atribuídas às crises sísmicas que ocorreram a partir de 1522 e constituem-se em uma peregrinação religiosa que, em vez de se dirigir a um templo ou lugar santo, ocorre ao redor da ilha de São Miguel, por entre atalhos e/ou caminhos principais.

Frei Agostinho de Monte Alverne elucida-nos da ocorrência de uma erupção vulcânica no vale das Furnas, concelho da Povoação em 1630 na sua obra "Crónicas da Província de São João Evangelista das Ilhas dos Açores" e que, como forma de penitência e de apelo por proteção divina, os habitantes da ilha percorreram a pé as casas de Nossa Senhora de noite e dia (ALVERNE, 1695).

Alguns relatos dos cronistas das ilhas açorianas, como Frei Diogo das Chagas, Padre António Cordeiro, Gaspar Frutuoso e Monte Alverne, indicam que estas peregrinações eram realizadas tanto por casais, como por famílias. Realidade que foi, inclusive, retratada em uma das obras do pintor Domingos Rebelo (1891-1975), de considerável renome nos Açores e em Portugal.

A proibição da incorporação feminina surgiu em 1707 por parte da hierarquia eclesiástica, juntamente com a extinção de bailes e instrumentos musicais, após a visita à paróquia de Nossa Senhora do Rosário da Lagoa, pois o visitante afirmou que estas práticas eram indecentes e indecorosas. Foi mais além ao apelar ao "poder masculino" dos maridos, pais, irmãos e tios a fim de impedirem a presença feminina.

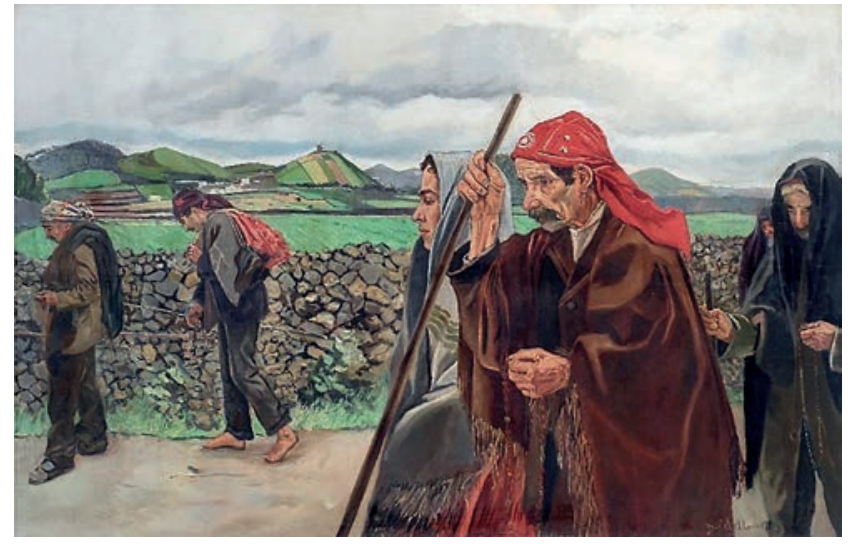

Figura 2 - Obra As promessas, de Domingos Rebelo, 1960. Óleo sobre tela

Fonte: Coleção do Museu Carlos Machado.

Fotografia de António Pacheco, 2010

Em 1743 as romarias foram proibidas completamente pela hierarquia eclesiástica, mas já o haviam sido desde 1705, ordem esta ignorada pelo povo, tornando esta devoção um cariz autônomo e popular.

Atualmente os romeiros param nas igrejas e ermidas das várias freguesias da ilha, mas nos seus primórdios apenas frequentavam os templos marianos sob a designação de "visita às casinhas ou capelinhas de Nossa Senhora" (PONTE, 2007). Neste ritual religioso encontramos determinadas particularidades como a permanência ao longo dos séculos, o traje do romeiro, a alimentação, a confraternização e a devoção à fé católica.

A quaresma é o período anual eleito para a manifestação, em contraponto à época caracterizada pelo entrudo, ou carnaval, onde a festa popular é composta por excessos em todos os campos da vida humana, individual e coletiva. A quarta-feira de cinzas marca o início de um tempo de penitência, jejum, abstinência, reflexão e oração, onde os entes falecidos também eram relembrados, até pelo menos no século $X X$, e todo o período era vivido com um espírito de disciplina, dentro dos ideais cristãos e católicos fortemente seguidos pelos açorianos.

A cada semana da quaresma partem em romaria diversos ranchos de várias freguesias da ilha e frequentemente das comunidades 
de emigrantes açorianos como do Canadá, Estados Unidos e Bermuda, como demonstra a tabela a seguir.

Tabela 1

\begin{tabular}{|c|c|c|c|}
\hline & Freguesia & Data de saida & Data de regresso \\
\hline 1 & Cabouco & 09/03/2019 & $16 / 03 / 2019$ \\
\hline 2 & Calhetas & 09/03/2019 & $16 / 03 / 2019$ \\
\hline 3 & Candelária & 09/03/2019 & $16 / 03 / 2019$ \\
\hline 4 & Arrifes - Milagres & 10/03/2019 & $17 / 03 / 2019$ \\
\hline 5 & Ribeira Quente e Furnas & 09/03/2019 & $16 / 03 / 2019$ \\
\hline 6 & Ribeirinha & 09/03/2019 & $16 / 03 / 2019$ \\
\hline 7 & São Pedro - Ponta Delgada & 09/03/2019 & $16 / 03 / 2019$ \\
\hline 8 & São Roque & 09/03/2019 & $16 / 03 / 2019$ \\
\hline 9 & Santa Bárbara - Ponta Delgada & 09/03/2019 & 16/03/2019 \\
\hline 10 & Várzea & 09/03/2019 & $16 / 03 / 2019$ \\
\hline 11 & Santa Maria - Toronto & 10/03/2019 & 17/03/2019 \\
\hline 12 & Conceição - Ribeira Grande & 16/03/2019 & 23/03/2019 \\
\hline 13 & Fajã de Cima & 16/03/2019 & 23/03/2019 \\
\hline 14 & Pilar da Bretanha & $16 / 03 / 2019$ & 23/03/2019 \\
\hline 15 & Ribeira Seca - Ribeira Grande & $16 / 03 / 2019$ & 23/03/2019 \\
\hline 16 & Vila de Nordeste e Pedreira & $17 / 03 / 2019$ & 24/03/2019 \\
\hline 17 & Sete Cidades & 16/03/2019 & 23/03/2019 \\
\hline 18 & São Pedro e Santo António- Nordeste & 16/03/2019 & 23/03/2019 \\
\hline 19 & São Sebastião - Toronto & $17 / 03 / 2019$ & 24/03/2019 \\
\hline 20 & Matriz de Ponta Delgada & 16/03/2019 & 24/03/2019 \\
\hline 21 & Vila da Povoação & 16/03/2019 & 24/03/2019 \\
\hline 22 & Covoada & 23/03/2019 & $30 / 03 / 2019$ \\
\hline 23 & Fajã de Baixo & 23/03/2019 & $30 / 03 / 2019$ \\
\hline 24 & Maia & 23/03/2019 & $30 / 03 / 2019$ \\
\hline 25 & Ponta Garça & 23/03/2019 & $30 / 03 / 2019$ \\
\hline 26 & Porto Formoso & 23/03/2019 & $30 / 03 / 2019$ \\
\hline 27 & Remédios Lagoa & 23/03/2019 & $30 / 03 / 2019$ \\
\hline 28 & São José - Ponta Delgada & 23/03/2019 & $30 / 03 / 2019$ \\
\hline 29 & Santo António - Ponta Delgada & 23/03/2019 & $30 / 03 / 2019$ \\
\hline 30 & Santa Bárbara - Ribeira Grande & 23/03/2019 & $30 / 03 / 2019$ \\
\hline 31 & Lomba da Fazenda & 24/03/2019 & 31/03/2019 \\
\hline 32 & Algarvia & 31/03/2019 & 07/04/2019 \\
\hline 33 & Capelas & $30 / 03 / 2019$ & 06/04/2019 \\
\hline 34 & Fenais da Ajuda & $30 / 03 / 2019$ & 06/04/2019 \\
\hline
\end{tabular}




\begin{tabular}{|c|c|c|c|}
\hline & Freguesia & Data de saida & Data de regresso \\
\hline 35 & Feteiras & $30 / 03 / 2019$ & 06/04/2019 \\
\hline 36 & Livramento & $30 / 03 / 2019$ & 06/04/2019 \\
\hline 37 & Lomba do Loução & $30 / 03 / 2019$ & 06/04/2019 \\
\hline 38 & Matriz da Ribeira Grande & $30 / 03 / 2019$ & 06/04/2019 \\
\hline 39 & Ribeira das Tainhas & $31 / 03 / 2019$ & 07/04/2019 \\
\hline 40 & Matriz de Vila Franca do Campo & $30 / 03 / 2019$ & 06/04/2019 \\
\hline 41 & Água d'Alto & 06/04/2019 & $13 / 04 / 2019$ \\
\hline 42 & Água de Pau & 06/04/2019 & 13/04/2019 \\
\hline 43 & Ajuda da Bretanha & 06/04/2019 & $13 / 04 / 2019$ \\
\hline 44 & Fenais da Luz & 06/04/2019 & $13 / 04 / 2019$ \\
\hline 45 & Feiteira Pequena e Santana & 07/04/2019 & 14/04/2019 \\
\hline 46 & Lombinha da Maia & 06/04/2019 & $13 / 04 / 2019$ \\
\hline 47 & Relva & 06/04/2019 & $13 / 04 / 2019$ \\
\hline 48 & Remédios da Bretanha & 06/04/2019 & $13 / 04 / 2019$ \\
\hline 49 & Santa Clara & 06/04/2019 & 13/04/2019 \\
\hline 50 & Matriz e Santa Cruz - Lagoa & 06/04/2019 & $13 / 04 / 2019$ \\
\hline 51 & São Brás & 07/04/2019 & 14/04/2019 \\
\hline 52 & Arrifes - Saúde & 06/04/2019 & $13 / 04 / 2019$ \\
\hline 53 & Pico da Pedra & $17 / 04 / 2019$ & 18/04/2019 \\
\hline 54 & Rabo de Peixe & $11 / 04 / 2019$ & 18/04/2019 \\
\hline 55 & Rosário & $17 / 04 / 2019$ & 18/04/2019 \\
\hline
\end{tabular}

Fonte: Elaborada pela autora

Os protagonistas do nosso tempo são homens entre os dez e oitenta anos aproximadamente, organizados em ranchos que variam entre os trinta e setenta elementos, podendo alguns ultrapassar estes valores.

A partida ocorre geralmente na madrugada de sábado após a celebração da eucaristia na paróquia de residência. Aqui tem lugar a despedida do romeiro e do seu núcleo familiar (Entrevista G. Silva, 2019): "Nós saímos do nosso bem-estar, da nossa vida habitual, portanto dia-a-dia, deixamos a nossa casa, nossos filhos, nossa esposa e todos os nossos haveres e saímos na caminhada em oração." (Entrevista C. Vieira, 2018).

O traje do romeiro é composto por um lenço ao pescoço, um xaile pelos ombros, um terço e um bordão nas mãos, uma cevadeira às costas e roupa e calçado confortável. O lenço pode ser também amarrado quando colocado à cabeça. Na cevadeira - saco de pano - são transportados alguns a limentos e uma muda de roupa. $O$ xale e o lenço adquiriram um padrão típico nas últimas décadas, mas no passado utilizavam o melhor que tinham em casa, geralmente das suas mães ou irmãs.

O rancho segue pelas estradas da itha em duas filas indianas. Ao meio, o primeiro da frente é o elemento mais jovem. Cabe-lhe carregar a cruz de Cristo de tamanho considerável. O grupo compõe-se hierarquicamente pelo "mestre", "contra-mestre", "guias", "ajudantes" um ou dois "romeiros-dispenseiros", o "alembrador 
das almas", o "procurador das almas" e os restantes romeiros, que se tratam entre si e às restantes pessoas com que se cruzam por "irmão" ou "irmã". (Entrevista C. Vieira, 2018)

O "mestre" é o líder da romaria. Assumia a grande responsabilidade de mantê-la em ordem, autorizando ou negando o que the era solicitado pelo rancho e por quem os restantes romeiros detinham uma obediência total (Entrevista J. Leite, 2019). Hoje a sua função é de cariz logístico e espiritual, essencialmente, quer através da orientação, do conselho ou da motivação, sendo responsável pela condução ao bom sucesso, através da caridade e justiça para com todos os irmãos.

Conserva a paz, a harmonia, o respeito e a disciplina, cabendo-lhe igualmente estar atento à saúde dos romeiros e gerir o horário diário para que o cumpram rigorosamente. É o mestre também que regula a marcha, determina as interrupções para descanso, necessidades fisiológicas e refeições. Sempre que possível realiza uma leitura bíblica e meditação ao iniciar o novo dia. Designa também o irmão que fará a oração em cada templo (oração da manhã, da noite e das refeições). Assume responsabilidades que implicam a segurança rodoviária do rancho, de data a efetuar a peregrinação, a distribuição das pernoitas, a definição do itinerário, entre outros. Por fim a tradição do rito e a exclusão de modificações ou alterações está sob a sua alçada (REGULAMENTO, 2017).

Muitas vezes o cansaço toca mais alto e começamos a falar pela cabeça e não pelo coração. Temos de saber se temos algum irmão com algum problema físico, temos de estar muito atentos. Algum irmão precisa de uma palavra amiga, sente-se desmotivado pelo cansaço e é aí que o mestre entra em acção. (Entrevista C. Vieira, 2018)

De maneira geral, o "contra-mestre" toma o lugar do mestre sempre que solicitado; os "guias" são responsáveis pela condução do percurso tradicionalmente estabelecido; e os "ajudantes" colaboram com o mestre nas orações, refeições e improvisos (REGULAMENTO, 2017).

Os "romeiros-dispenseiros" são os encarregados da alimentação do rancho e os únicos que podem abandonar provisoriamente o grupo para adquirirem mantimentos (LEAL, 1994). No entanto, a alimentação do romeiro é muito simples, baseando-se em uma sopa, pão ou bolo lêvedo,' podendo incluir alguma refeição quente esporadicamente. A prioridade é dada à água e à hidratação (Entrevista C. Vieira, 2018).

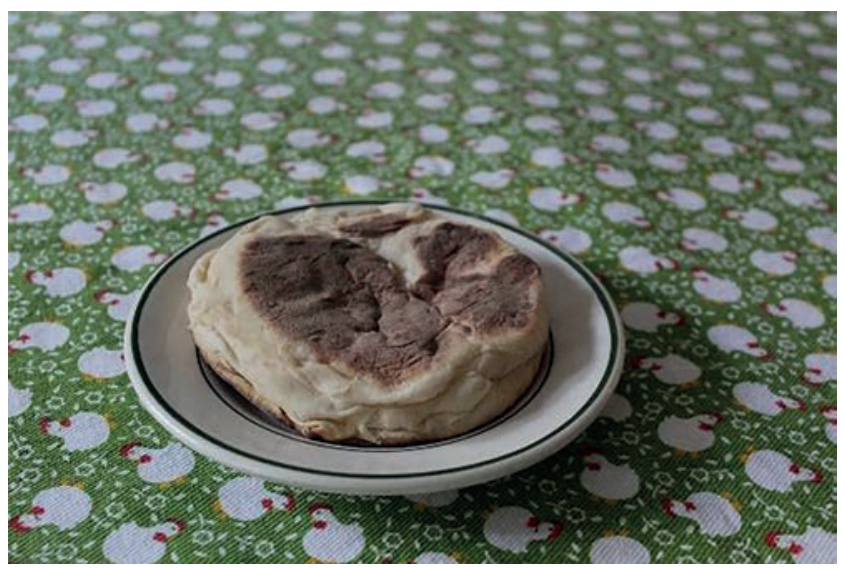

Figura 3 - Bolo lêvedo

Fonte: Fotografia de Creusa Raposo, 2019

Em loco verificou-se ainda o consumo de bebidas gaseificadas e de uma refeição quente composta essencialmente por feijão e carne de porco, quando de uma paragem no Miradouro da Ponta do Sossego. A cruz foi colocada sobre a mesa e alguns romeiros alimentaram-se sentados à junto dela, enquanto outros preferiram degustar a refeição isolados ou em contemplação do mar e das árvores em redor.

O "alembrador das almas" e o "procurador das almas" são os encarregados de recolher as intenções de oração junto dos irmãos que os procuram na via ou que os interpelem nos

1 Iguaria típica da ilha de São Miguel, inicialmente confeccionada na localidade de Furnas. Define-se por ser um pão doce de forma arredondada e tamanho médio. É igualmente referenciado por bolo inchado. 
templos. Quando obtêm um terço completo de orações solicitadas, o mestre é informado, e em uma zona privada o terço é rezado. As intenções dizem respeito à vida privada dos micaelenses, geralmente por situações graves (Entrevista A. Nascimento, 2018), e estes também o são igualmente responsáveis pelas orações especiais, como por exemplo ao passar pelos cemitérios (REGULAMENTO, 2017).

A "Ave-Maria dos romeiros" é um cântico característico destas romarias, construído a partir da oração da Ave-Maria (Entrevista A. Massa, 2019). É cantado em coro e da qual Bettencourt da Câmara, citado por João Leal, afirma ter influências do cantochão combinado com elementos de natureza popular (LEAL, 1994). Mais conhecido por canto gregoriano, é um cântico tradicional da igreja católica que consiste em uma única melodia de textura monofônica composto sobre textos litúrgicos latinos e de origem judaica.

A "Ave-Maria dos romeiros" ocorre em responsorial, onde o solista intercala com o coro. Outros cânticos podem ser cantados em direto, ou seja, sem alternância entre o solista e o coro. O terço também é rezado principalmente quando o rancho caminha por entre "escampados", que são zonas de difícil movimentação e expostas às intempéries: "nós somos sessenta e dois irmãos de Vila Franca do Campo. A irmã vai desejar alguma oração? Uma Ave-Maria pelas almas do purgatório. Está entregue, irmã. Que Nosso Senhor fique consigo." (Entrevista A. Nascimento, 2018).

É igualmente frequente a aproximação de cidadãos a fim de perguntarem o número de romeiros. A resposta indicada contempla os elementos do rancho e a Santíssima Trindade a fim de orarem por uma boa caminhada destes (Entrevista C. Vieira, 2018).

Eu passei e ela deu-me sinal, eu fui lá e disse: "Boa tarde, irmã" - e ela: - "Aí ir mão" - e ela pôs-me logo a mão por cima do meu ombro. - "Ah irmão, tenho um pedido a fazer. Vocês rezem que eu tenho o meu neto quase na hora da morte" - e ela quando disse aquilo as lágrimas veio-me logo aos olhos e a resposta que eu disse a ela: "A irmã fique descansada que agente vamos rezar por ele que Deus é grande e vai dar a alegria à irmã". E ela: "Posso beijar o seu crucifixo?" - Eu disse: - "Sim" - e ela beijou. No ano seguinte eu passei e ela estava à porta. Fui ter com ela e ela pôs-me logo a mão e abraçou-me: - "Oh irmão a sua oração foi correcta, o meu neto está bom". (Entrevista C. Saeita, 2018)

É frequente que os últimos romeiros utilizem faixas de material fluorescente, permitindo a fácil identificação, dado que nas últimas décadas, uma das principais preocupações é evitar os acidentes de viação. O micaelense parte em romaria motivado pela fé em Deus e pela religião Católica Romana.

Em tempos cumpriam as promessas de outrem, ou seja, agradeciam de forma física por uma graça recebida pela família e que geralmente era prometida pela mãe ou pai do romeiro. Situações de doença eram frequentes, mas também desfortúnios associados à história das ilhas e do país, como por exemplo a Guerra Colonial Portuguesa ou a pretensão de incorporar as várias vagas de emigração para o Canadá, Bermuda e Estados Unidos da América em busca de melhores condições de vida.

Porém, nas últimas décadas os romeiros procuram um encontro espiritual consigo, com Deus e com a natureza (Entrevista T. Silva, 2018). O objetivo principal é a evolução como seres humanos de forma a serem "um pouco melhores, melhores pais, melhores maridos, melhores amigos." (Entrevista R. Batista, 2018).

O romeiro é, portanto, um homem que acredita profundamente em Deus e que incorpora a romaria com o intuito de elevar o seu espírito e tornar-se melhor cidadão (Entrevista V. Santos, 2018).

Não raras vezes o romeiro repete anualmente este ritual, que aliás é incentivado e transmitido de geração em geração (Entrevista 


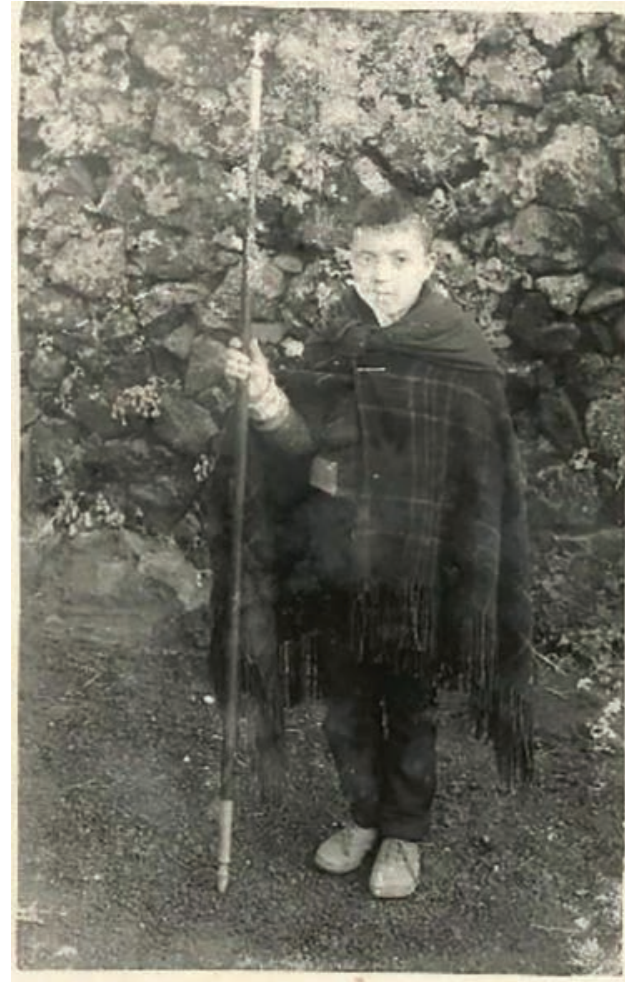

Figura 4 - Romeiro adolescente

Fonte: Fotografia cedida pelo Sr. Gil Silva, década de sessenta do século XX

P. Resendes, 2018). As crianças da ilha crescem com esta tradição, ouvindo sobre o assunto. Algumas escolas elaboram exposições temáticas e recriam o rito. Como resultado incorporam os ranchos de romeiros crianças e adolescentes de várias idades motivados muitas vezes pela curiosidade (Entrevista C. Vieira, 2018).

Eu tenho 14 anos. Já é o terceiro ano que vou. O meu pai ia de romeiro e eu gostava de experimentar. Fui e gostei. P'ro ano se puder eu venho. - O que vais pensando? - Penso como será o dia, rezo por mim, pelo Papa Francisco, pela minha família. (Entrevista L. Oliveira, 2018)

Uma das características fundamentais deste ritual é o isolamento da sociedade (LEAL, 1994). Este afastamento ocorre para com o núcleo familiar principal, composto por filhos, pais e esposas, e para com as tarefas do dia a dia, como emprego e relações com colegas e patrão. É frequente as

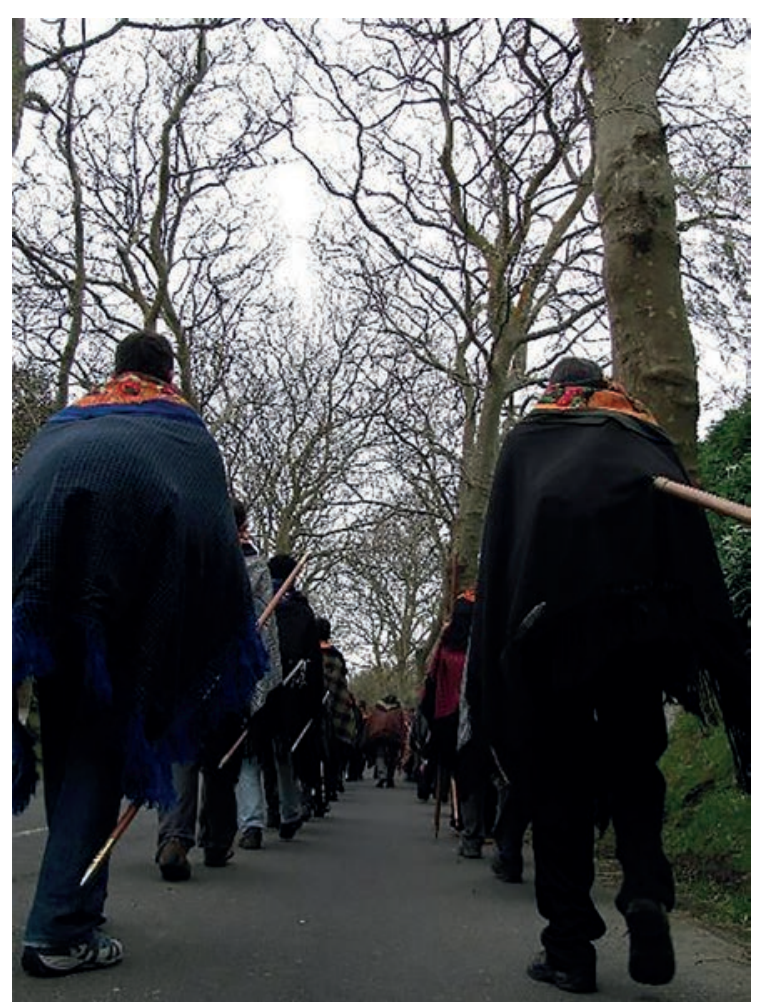

Figura 5 - Romeiros

Fonte: Fotografia de Eduardo Borges, 2012

esposas comentarem a ausência dos maridos com grandes lamentações e em resposta recebem frases do gênero: "levas o ano todo que não vês o teu homem e basta ele estar uma semana fora para estares com saudades. Deixa-o, mas é estar na romaria." (Entrevista C. Vieira, 2018).

O romeiro em momento algum pode abandonar o rancho, ou cumprimentar ou visitar familiares e amigos ao longo do percurso. Também não pode fumar, comer ou usar telefone móvel enquanto o rancho está em andamento (REGULAMENTO, 2017).

A oração e a penitência são fatores que especializam este ritual. Todo o percurso em redor da ilha, no sentido dos ponteiros do relógio, é feito a rezar, a meditar e a cantar (Entrevista C. Vieira, 2018).

O itinerário contempla os seis conselhos da itha de São Miguel e cerca de cem templos católicos. Com uma configuração circular e predominantemente realizada pelo litoral atinge uma extensão aproximada de $200 \mathrm{~km}$, ilustrados pela tabela que a seguir se apresenta (LEAL, 1994). 
O silêncio também é valorizado e considerado fundamental na aproximação para com Deus e com a natureza de modo a alcançar a conversão (Entrevista T. Silva, 2018).

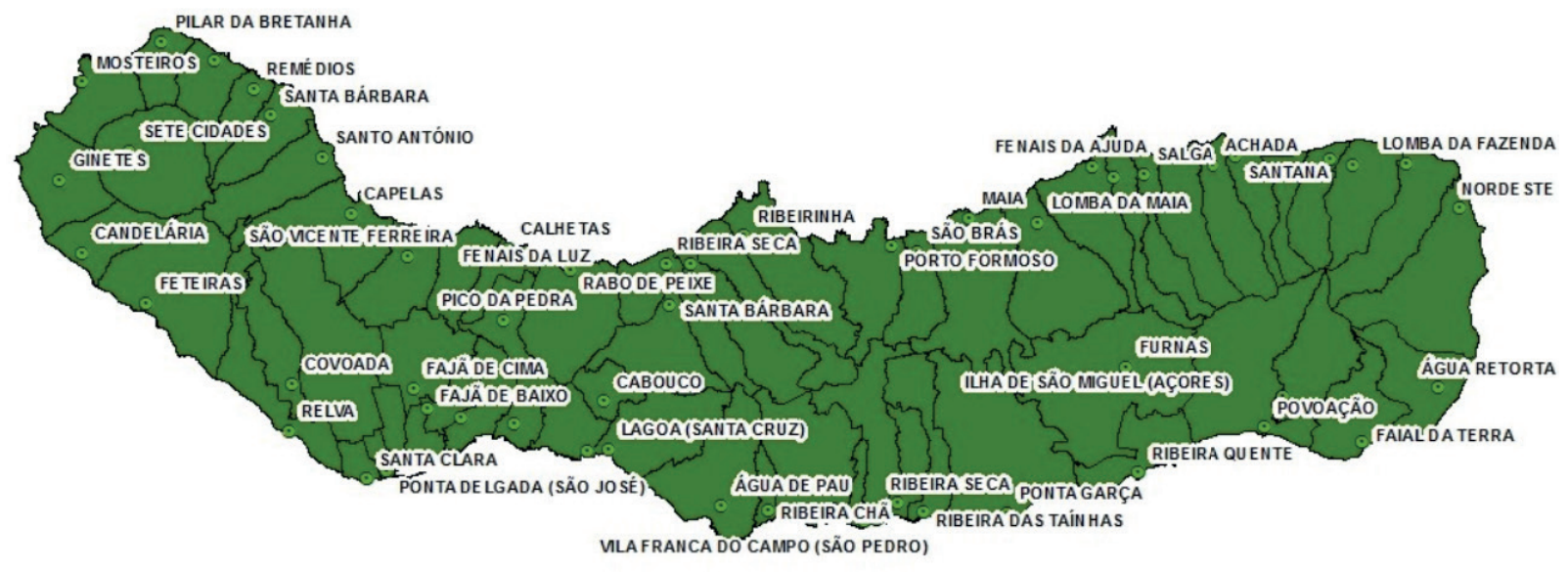

Legenda:

- Sede de Freguesia

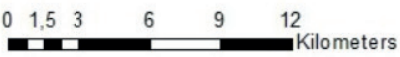

Figura 6 - Mapa da ilha de São Miguel

Fonte: <https://sites.google.com/site/islandsaomiguel/mapa-da-ilha>

Romeiro:

Seja bendita e louvada a Sagrada Vida, Paixão, Morte e Ressurreição de Nosso Senhor Jesus Cristo". Rancho: "Seja para sempre louvado com Sua e Nossa Mãe, Maria Santíssima". Romeiro: "Gloria ao Pai, ao Filho, ao Espírito Santo, assim como era no princípio, agora e sempre. Amém". Romeiro: "Irmãos, eu estou aqui diante da igreja de Santo António Nordestino (...) pedi a ele que também olhe pelas causas que tanto aspiramos. P'ra isto uma Avé-Maria" (oração de improviso). Romeiro: "Santo é o fruto do teu ventre, Santa Mãe, Santa Maria mãe de Deus e nossa mãe, rogai pelos pecadores, hoje e sempre até ao céu, Salvé".

Tabela 2

\begin{tabular}{|l|l|l|l|}
\multicolumn{2}{|c|}{ Concelho } & \multicolumn{1}{|c|}{ Freguesia } & \multicolumn{1}{c|}{ Templo } \\
\hline 1 & Vila Franca do Campo & Ponta Garça & Senhora da Vida \\
\hline 2 & Vila Franca do Campo & Ribeira das Tainhas & Bom Jesus Menino \\
\hline 3 & Vila Franca do Campo & São Miguel & Senhora da Paz \\
\hline
\end{tabular}


Concelho

Freguesia

Templo

\begin{tabular}{|c|c|c|c|}
\hline 4 & Vila Franca do Campo & São Miguel & Santo André \\
\hline 5 & Vila Franca do Campo & São Miguel & Mãe de Deus \\
\hline 6 & Vila Franca do Campo & São Miguel & São Miguel \\
\hline 7 & Vila Franca do Campo & São Miguel & Bom Jesus da Pedra \\
\hline 8 & Vila Franca do Campo & São Miguel & Senhora da Natividade \\
\hline 9 & Vila Franca do Campo & São Pedro & São Pedro \\
\hline 10 & Vila Franca do Campo & São Pedro & Senhora de Fátima \\
\hline 11 & Vila Franca do Campo & Água de Alto & São Lázaro \\
\hline 12 & Lagoa & Ribeira Chã & São José \\
\hline 13 & Lagoa & Água de Pau & Senhora das Dores \\
\hline 14 & Lagoa & Água de Pau & Senhora dos Anjos \\
\hline 15 & Lagoa & Matriz & Santa Cruz \\
\hline 16 & Lagoa & Rosário & Senhora do Rosário \\
\hline 17 & Lagoa & Atalhada & Senhora das Necessidades \\
\hline 18 & Ponta Delgada & Livramento & Senhora do Livramento \\
\hline 19 & Ponta Delgada & Livramento & Senhora do Carmo \\
\hline 20 & Ponta Delgada & Livramento & Senhora da Glória \\
\hline 21 & Ponta Delgada & São Roque & São Roque \\
\hline 22 & Ponta Delgada & Fajã de Baixo & São João de Deus \\
\hline 23 & Ponta Delgada & Fajã de Baixo & Senhora dos Anjos \\
\hline 24 & Ponta Delgada & Fajã de Cima & Senhora da Oliveira \\
\hline 25 & Ponta Delgada & Matriz & São Sebastião \\
\hline 26 & Ponta Delgada & São José & São José \\
\hline 27 & Ponta Delgada & São José & Senhor Santo Cristo \\
\hline 28 & Ponta Delgada & Arrifes & Senhora da Conceição \\
\hline 29 & Ponta Delgada & Arrifes & Senhora da Piedade \\
\hline 30 & Ponta Delgada & Arrifes & Senhora dos Milagres \\
\hline 37 & Ponta Delgada & Arrifes & Senhora da Saúde \\
\hline 32 & Ponta Delgada & Covoada & Senhora da Ajuda \\
\hline 33 & Ponta Delgada & Feteiras & Santa Luzia \\
\hline 34 & Ponta Delgada & Candelária & Senhora das Candeias \\
\hline 35 & Ponta Delgada & Candelária & Senhora do Socorro \\
\hline 36 & Ponta Delgada & Ginetes & São Sebastião \\
\hline 37 & Ponta Delgada & Ginetes & Senhora de Fátima \\
\hline 38 & Ponta Delgada & Várzea & Sagrada Família \\
\hline 39 & Ponta Delgada & Sete Cidades & São Nicolau \\
\hline 40 & Ponta Delgada & Mosteiros & Senhora da Conceição \\
\hline
\end{tabular}




\begin{tabular}{|c|c|c|c|}
\hline & Concelho & Freguesia & Templo \\
\hline 41 & Ponta Delgada & Pilar da Bretanha & Senhora da Conceição \\
\hline 42 & Ponta Delgada & Pilar da Bretanha & Senhora do Pilar \\
\hline 43 & Ponta Delgada & Ajuda da Bretanha & Senhora da Ajuda \\
\hline 44 & Ponta Delgada & Remédios da Bretanha & Senhora dos Remédios \\
\hline 45 & Ponta Delgada & Santa Bárbara & Santa Bárbara \\
\hline 46 & Ponta Delgada & Santo António & Santo António \\
\hline 47 & Ponta Delgada & Capelas & Senhora da Apresentação \\
\hline 48 & Ponta Delgada & Capelas & Senhora do Rosário \\
\hline 49 & Ponta Delgada & São Vicente & Senhora da Conceição \\
\hline 50 & Ponta Delgada & Fenais da Luz & Senhora da Luz \\
\hline 51 & Ribeira Grande & Calhetas & Senhora da Boa Viagem \\
\hline 52 & Ribeira Grande & Calhetas & Senhora das Mercês \\
\hline 53 & Ribeira Grande & Rabo de Peixe & Senhora do Rosário \\
\hline 54 & Ribeira Grande & Rabo de Peixe & Jesus Crucificado \\
\hline 55 & Ribeira Grande & Ribeira Seca & São Pedro \\
\hline 56 & Ribeira Grande & Conceição & Senhora do Guadalupe \\
\hline 57 & Ribeira Grande & Conceição & Senhora da Conceição \\
\hline 58 & Ribeira Grande & Matriz & Senhor dos Passos \\
\hline 59 & Ribeira Grande & Matriz & Senhora da Estrela \\
\hline 60 & Ribeira Grande & Matriz & Senhora de Fátima \\
\hline 61 & Ribeira Grande & Ribeirinha & São Salvador do Mundo \\
\hline 62 & Ribeira Grande & Porto Formoso & Senhora da Graça \\
\hline 63 & Ribeira Grande & São Brás & São Brás \\
\hline 64 & Ribeira Grande & Gorreana & Senhora do Resgate \\
\hline 65 & Ribeira Grande & Maia & Divino Espírito Santo \\
\hline 66 & Ribeira Grande & Lombinha da Maia & Senhora das Dores \\
\hline 67 & Ribeira Grande & Lomba da Maia & Senhora do Rosário \\
\hline 68 & Ribeira Grande & Ribeira Funda & Senhora da Aflição \\
\hline 69 & Ribeira Grande & Fenais da Ajuda & Reis Magos \\
\hline 70 & Ribeira Grande & Fenais da Ajuda & Senhora da Ajuda \\
\hline 71 & Ribeira Grande & Lomba de São Pedro & São Pedro \\
\hline 72 & Nordeste & Salga & São José \\
\hline 73 & Nordeste & Achadinha & Senhora do Rosário \\
\hline 74 & Nordeste & Achada & Senhora da Anunciação \\
\hline 75 & Nordeste & Feteira Pequena & Santa Ana \\
\hline 76 & Nordeste & Algarvia & Senhora do Amparo \\
\hline 77 & Nordeste & Santo António & Santo António \\
\hline
\end{tabular}




\begin{tabular}{|c|c|c|c|}
\hline & Concelho & Freguesia & Templo \\
\hline 78 & Nordeste & São Pedro & São Pedro \\
\hline 79 & Nordeste & São Pedro & Senhor do Pranto \\
\hline 80 & Nordeste & Lomba da Fazenda & Senhora da Conceição \\
\hline 81 & Nordeste & Vila de Nordeste & São Jorge \\
\hline 82 & Nordeste & Vila de Nordeste & Senhora da Nazaré \\
\hline 83 & Nordeste & Pedreira & Senhora da Luz \\
\hline 84 & Povoação & Água Retorta & Senhora da Penha de França \\
\hline 85 & Povoação & Faial da Terra & Senhora da Graça \\
\hline 86 & Povoação & Vila da Povoação & Senhora dos Remédios \\
\hline 87 & Povoação & Vila da Povoação & Mãe de deus \\
\hline 88 & Povoação & Vila da Povoação & Senhora do Rosário \\
\hline 89 & Povoação & Ribeira Quente & São Paulo \\
\hline 90 & Povoação & Furnas & Senhora da Alegria \\
\hline 91 & Povoação & Furnas & Santa Ana \\
\hline 92 & Povoação & Furnas & Senhora da Vitória \\
\hline 93 & Vila Franca do Campo & Ponta Garça & Senhora das Mercês \\
\hline 94 & Vila Franca do Campo & Ponta Garça & Senhora da Piedade \\
\hline
\end{tabular}

A caminhada é revestida de um sentido penitencial, primeiro pelas características geomorfológicas da ilha onde marcam presença vales, montes, picos, ribeiras, entre outros. Em segundo lugar, pela ausência de eletricidade que só surgiu na ilha a partir de 1900 (INSULANA, 1953, p. 41-61), propagando-se de forma lenta e culminando a sua electrificação total nos anos 1970 do século XX (Entrevista L. Martins, 2015). Uma das formas de amenizar as circunstâncias era através de atalhos e canadas, mas continuavam à mercê do clima, chuvoso, da humidade elevada e de temperaturas relativamente baixas (Entrevista G. Silva, 2019).

Muitas vezes os romeiros realizavam o percurso descalços, traduzindo a miséria e a pobreza da região, e alguns cumpriam o ritual a pão e água intensificando ao máximo a penitência a fim de espiar os seus pecados e os alheios (LEAL, 1994). Atualmente, não se realiza mais o ritual descalço, mas alguns permanecem a pão e água por promessa individual, no entanto, o ritmo diário do percurso continua rígido e meticulosamente controlado, iniciando-se com o despertar pelas 2h30min. da madrugada e com o andamento às $4 \mathrm{~h}$. Por média caminham diariamente cerca de quinze horas, chegando à pernoita pelas $19 \mathrm{~h}$ (Entrevista C. Vieira, 2018).

A dureza da penitência torna-se evidente ao longo do passar das horas com vários tipos de sequelas (bolhas e calos nos pés, dores musculares etc.) e cansaço geral (LEAL, 1994, p. 246). Nas paragens autorizadas pelo mestre os romeiros aproveitam para cuidar das feridas ou para receberem massagens com pomadas. Sentam-se ou deitam-se nos passeios a repousar. Este momento termina com o tocar de uma pequena sineta.

Outra grande característica deste ritual prende-se com a relação que os romeiros possuem entre si. A fraternidade exterioriza-se não só por se tratarem por "irmãos", mas por se relacionarem como tal. Saúdam-se habitualmente com um abraço. Definem-se como membros de uma mesma família, onde praticam a camaradagem e a solidariedade (Entrevista T. Silva, 2018). Num encontro entre ranchos foi possivel visualizar os romeiros cumprimentarem-se envolvendo cada um a sua mão direita e beijando a do irmão, dado que o rancho local lhes cedeu instalações para repousarem. 
A harmonia é de tal ordem importante que em caso de diferenças entre romeiros se deve promover um pequeno ritual de reconciliação, num local apropriado, escolhido pelo mestre onde tocará a pequena sineta. Aqui os incompatibilizados são convidados a abraçarem-se. O mestre ainda poderá determinar que caminhem lado-a-lado durante a romaria e a pernoitarem juntos a fim de incentivar a renovação da amizade entre eles.(LEAL, 1994, p. 250).

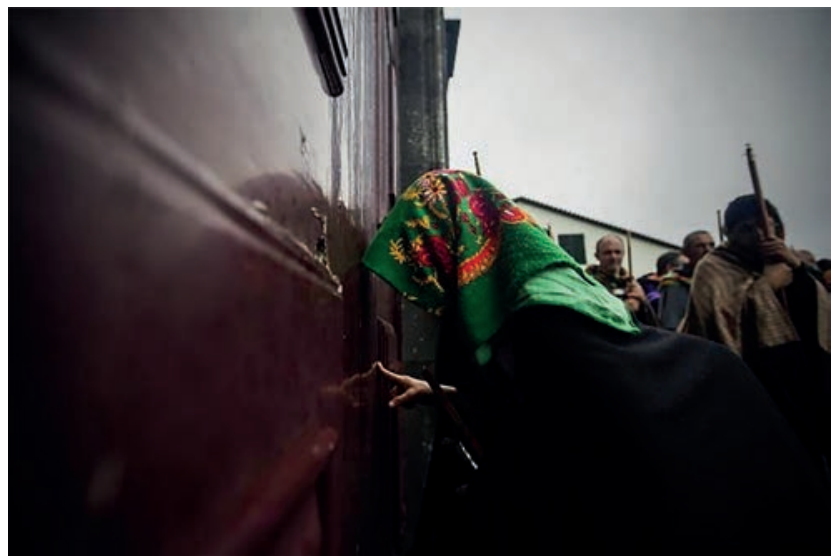

Figura 7 - Romeiro à porta do templo Fonte: Fotografia de Rui Oliveira, 2018
Quando se deparam com uma igreja, ermida ou capela é realizada uma paragem com oração, mesmo que o templo se encontre fechado. Nos que se encontram abertos entram, pedindo licença ao patrono ou à padroeira do templo. À porta deixam os seus bordões, quer no chão, quer encostados à parede. Em caso de ocorrer a eucaristia a oração ocorre à porta e em voz baixa sem perturbar o culto. Por se realizar na Quaresma é frequente os romeiros encontrarem o Santíssimo exposto. Assim efectuam orações e preces, geralmente ajoelhados e sob o intermédio da Virgem Maria.

A pernoita consiste na distribuição dos romeiros em residências ou locais de acolhimento onde jantam, tomam banho e dormem. No passado a pernoita podia ser mais um acto de penitência pelas deficientes condições, onde frequentemente dormiam nos bancos de madeira das igrejas. Por mais pobre que fosse uma familia, ao acolher um romeiro, apresentava-lhe a melhor comida que possuía e a melhor cama. Era frequente as senhoras secarem as roupas dos romeiros junto ao forno de lenha, a fim de serem utilizadas no dia seguinte.

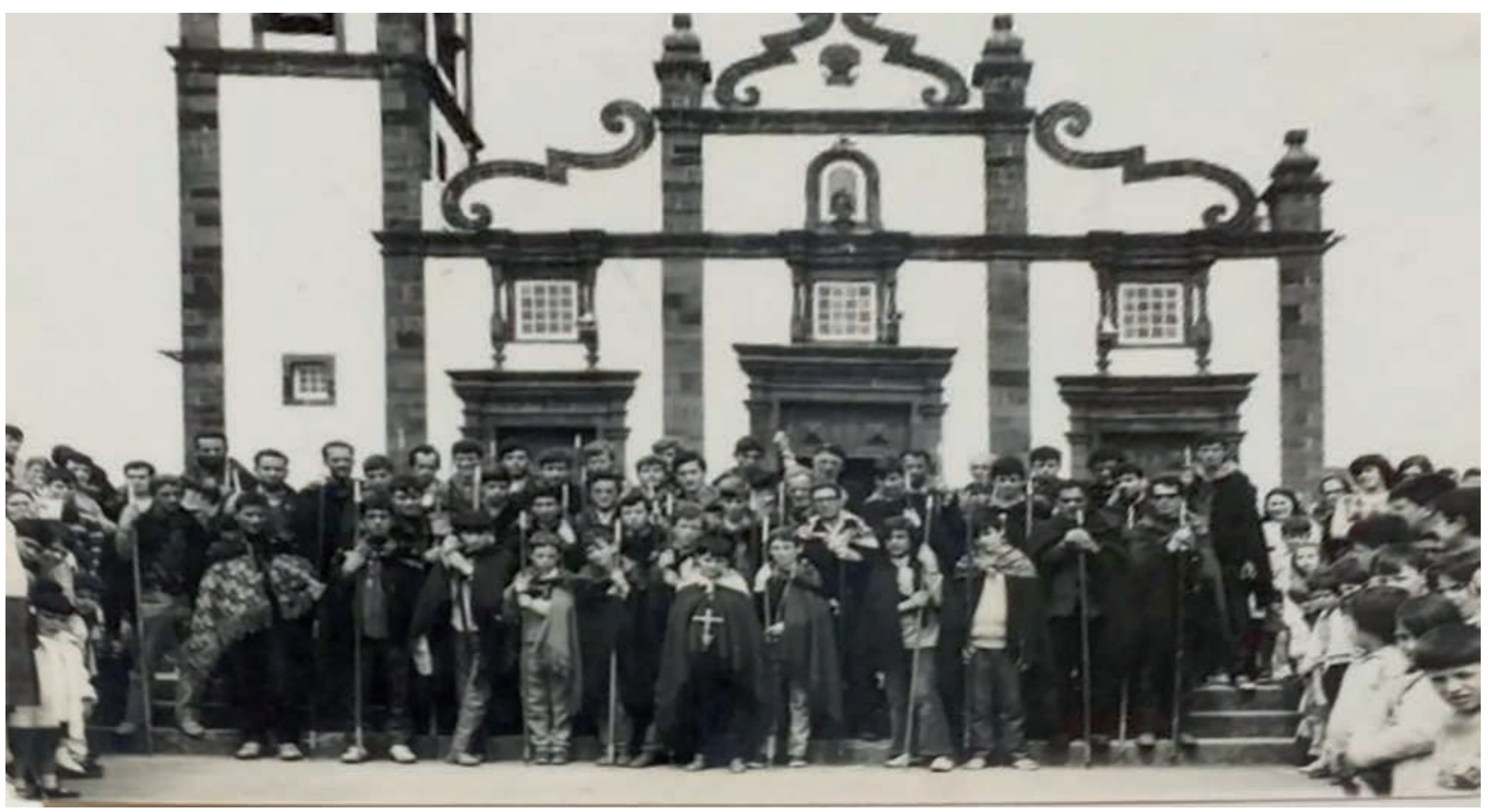

Figura 8 - Rancho de Romeiros da paróquia de N. ${ }^{a}$ Sr. $^{a}$ da Saúde antes da partida Fonte: Fotografia gentilmente cedida pelo Sr. Gil Silva, década de sessenta do séc. XX 
No entanto, algumas penitências eram acentuadas com a recusa de tomar banho, de fazer a barba ou a preferência por dormirem no chão (Entrevista G. Silva, 2019). Hoje a maior parte é acolhida pelas casas das freguesias por onde passam ou em casos extremos as juntas de freguesia providenciam espaços como salões comunitários ou polivalentes escolares para o efeito. Não raras vezes foram acolhidos pelo Regimento de Guarnição n. ${ }^{\circ} 2$, na freguesia de Arrifes em Ponta Delgada.

A chegada ocorre geralmente no Domingo de manhã, à hora da eucaristia habitual. Aqui são aguardados pelas famílias onde após a missa se dá um reencontro caloroso e termina a romaria (Entrevista G. Silva, 2019).

\section{Considerações finais}

As romarias quaresmais da ilha de São Miguel possuem origens que remontam ao século XVI a propósito de fenómenos naturais de origem vulcânica. Apesar de proibidas pela igreja perduraram até aos nossos dias por terem adquirido um cariz autocéfalo.

Durante a Quaresma partem em peregrinação em redor da ilha do Arcanjo São Miguel visitando os templos católicos em grupos de dimensões consideráveis e de várias faixas etárias. O traje do romeiro foi padronizado de forma a ser facilmente identificado, assim como o seu canto de inspiração gregoriana. A sua alimentação é modesta, tal como a sua rotina. Durante uma semana o rancho vivencia a sua fé através da oração, meditação, do silêncio, do afastamento da sociedade, da penitência, da fraternidade e partilha. O objetivo do romeiro é o de encontrar-se com Deus e com a natureza a fim de ser uma pessoa melhor dentro da sua comunidade.

\section{Referências}

ALMEIDA, R. Território e paisagem na Ilha de São Miguel: séculos XV a XVIII. Ponta Delgada: Direcção Regional da Cultura, Presidência do Governo Regional dos Açores, 2012.

ALVERNE, A. Crónicas da Provincia de S. João Evangelista das Ilhas dos Açores. v. 2. Ponta Delgada: Instituto Cultural de Ponta Delgada, 1961. ASSOCIAÇÃO DOS ROMEIROS DE SÃO MIGUEL. Regulamento do Movimento Romeiro de São Miguel. Açores, 2017.

FRUTUOSO, G. Saudades da terra: livro IV. Ponta Delgada: Presidência do Governo Regional dos Açores; Instituto Cultural de Ponta Delgada, 2005.

INSULANA. José Cordeiro (engenheiro). Ponta Delgada: Órgão do Instituto Cultural de Ponta Delgada, 1953.

LEAL, J. As festas do Espírito Santo nos Açores - um estudo de Antropologia Social. Lisboa: Publicações Dom Quixote, 1994.

PONTE, C. Romeiros de S. Miguel: entre a tradição e inovação. Da oralidade ao texto escrito. 2008. 406 f. Tese (Doutorado) - Universidade de Poitiers, Poitiers, França, 2008.

RAPOSO, C. Arrifes: urbanismo e património construído. 2016. 165 f. Dissertação (Mestrado) - Universidade dos Açores. Ponta Delgada, Açores, 2016.

SANTOS, J. Os Açores nos séculos XV e XVI. V. 1. Angra do Heroísmo: Direcção Regional dos Assuntos Culturais; Secretaria Regional da Educação e Cultura, 1989. 
